Safety and Security Engineering VIII 33

\title{
TRAINING EFFECTIVENESS ANALYSIS OF OSHA SILICA AND EXCAVATION STANDARDS FOR CONSTRUCTION
}

\author{
EMRAH KAZAN, MUMTAZ USMEN, BEDEL DESRUISSEAUX, \\ SERHAN KAYA \& MUSSIE SEYOUM \\ Civil and Environmental Engineering Department, Wayne State University, USA
}

\begin{abstract}
As construction safety and health standards evolve due to changing industry practices and stakeholder expectations, and the mandates get stronger on compliance with these standards, the need for training programs become more pronounced. This paper covers the training material development and program delivery and evaluation efforts associated with two standards promulgated by the US Department of Labor Occupational Safety and Health Administration (OSHA), namely Respirable Crystalline Silica (29 CFR 1926.1153) and Excavation and Trenching Safety (29 CFR 1926 Subpart P). The work reported here was undertaken through OSHA's Susan Harwood program. The developed training materials consisted of PowerPoint instructional modules; pre-tests and post-tests to measure incremental knowledge improvement; and trainee opinion surveys to evaluate the efficacy of the training materials and training delivery systems incorporated in the programs. Trainees included employees and employers representing various trades (operating engineers, laborers, masons, bricklayers, pipelayers and others). The delivery was performed by a traditional classroom format for the silica training, while lecture-based traditional and online training were separately offered for excavation safety. Kirkpatrick's model for learning assessment was adopted, employing level 1 and level 2 evaluations. It was found that both the lecture-based traditional and online training delivery were effective tools, although they have their advantages and disadvantages. Based on a limited study using cross-tabulation, no statistically significant correlation could be identified between levels 1 and 2 assessment results.
\end{abstract}

Keywords: training effectiveness, Kirkpatrick model, OSHA standards, respirable crystalline silica, excavation and trenching safety, traditional and online training.

\section{INTRODUCTION}

Construction is recognized as a high hazard industry in the US, as well as globally. A wide range of construction tasks and activities expose workers to physical dangers and/or health hazards, and if safe work practices are not followed, the consequences can be severe and costly. In the US alone, the annual total costs of fatal and non-fatal injuries in the construction industry is estimated to be over $\$ 10$ billion. Research and practice have shown that effective safety training is a critical part of achieving workplace safety. This can enhance the workers' recognition and understanding of potential hazards, and improve their safety responses accordingly to avoid injury, illness and fatality.

According to the annual data published by the Bureau of Labor Statistics (BLS), there were 194,300 injuries and 3,800 illnesses reported for the construction industry in 2018. Although there have been improvements in these statistics over the past few decades, these numbers are still considered high and unacceptable. On the other hand, 971 construction worker fatalities were recorded in 2017, and this number has been persistently high over the over the same period, reflecting critical needs to take corrective action. Broader adoption of company health and safety programs by the private construction sector with an effective training component is considered essential to improve the safety culture and reduce injuries, illnesses and fatalities in order to provide workplaces that are free of hazards.

The Occupational Safety and Health Administration (OSHA) promulgates and enforces safety and health standards applicable to all industries; however, it is noteworthy that there 
are a set of standards specifically applicable to construction (29 CHR 1926) because of its unique characteristics. Due to factors such as the fragmentation of project participants, large forces involved in constructing the structures using various equipment and tools, highly variable and sometimes difficult-to-control site conditions, and the transient/seasonal nature of the workforce, construction is viewed as an area requiring special focus [1]. Besides site inspections resulting in citations and penalties for safety violations, OSHA has also developed and delivered technical support and training programs to reach out to the industry with the objective of increasing the safety awareness of the workforce in critical high hazard areas, while aiming to impart better knowledge and skills needed for safer operations. The Susan Harwood program is one such initiative that competitively avails funding to non-profit agencies and educational institutions on an annual basis. Funding awardees develop and implement training programs on targeted topics to workers in industry sectors experiencing high injury, illness and fatality. Typically, the scope of work under the grant covers training material development, training delivery, and training effectiveness evaluation. For each grant, there is an expectation that the grantee trains a minimum number of eligible personnel on selected topic(s) and reports the number of training hours completed in the process. Approval of the training materials and delivery systems, grant monitoring and training observations are OSHA's responsibility, and the grant team submits quarterly and close-out reports to OSHA for review, feedback and approval. In most cases, the grantees collaborate with industry training experts and leaders by forming an advisory committee that provides guidance and feedback to the project team, while also assisting with the identification and recruitment of the trainees.

We have received and completed two Susan Harwood grants in the past few years; one on Respirable Crystalline Silica training and another on Excavation and Trenching Safety training. The impetus for OSHA to solicit training grant proposals for silica training through the Susan Harwood program was the continuing health concerns regarding the exposure of construction workers to excessive amounts of silica dust (possibly leading to silicosis and lung cancer), prompting it to issue a new standard (29 CFR 1926.1153) and making relevant training resources available to employees and employers nationwide, so useful information and knowledge on the contents of the standard (29 CFR 1926.1153) could be disseminated to appropriate groups and individuals to facilitate better compliance. Our second training grant was on excavation and trenching safety, which was funded by Susan Harwood especially because the fatality statistics on trench cave-ins and other serious excavation related accidents called for continuation and reinforcement of transfer of knowledge on the OSHA standard to targeted audiences. We were able to train a total of 721 people on silica in 2,163 contact hours, and 405 people on excavation safety in 1,215 contact hours through these grant efforts. While implementing these activities, we collected a considerable amount of demographic and knowledge gain and improvement data, and were able to analyse this data to learn about training effectiveness evaluation. This paper presents the results of these analyses and draws conclusions on the approaches that can be taken for training delivery and their effectiveness.

\section{OBJECTIVES AND APPROACH}

Given the mission of the Susan Harwood program, the main objective of our grants were to identify and train a minimum number of eligible personnel in the construction industry while achieving a minimum threshold of training contact hours (excluding preparation and travel). In accordance with our proposals, we committed to prepare PowerPoint training modules on the targeted topics; to present these modules to targeted audiences that need to be trained; 
and to evaluate the effectiveness of the training materials, delivery and the overall program. The tasks performed by our research team included the following:

- Preparation of the training materials, including PowerPoint modules (consisting of text, graphics, photos and videos), a pre-test and post-test(s) measuring the knowledge gain/improvement from the instruction, and an opinion survey questionnaire to capture demographic information and record the perceptions of the trainees regarding the efficacy and effectiveness of the training they received.

- Delivery of the training content (via PowerPoint slides) to groups or individuals categorized as employees or employers, representing construction trades, such as operating engineers, laborers, masons, bricklayers, and others using traditional classroom lectures (with demonstrations as needed), or by allowing them to take the same training online, facilitated by an internet portal developed by our team.

- Collection of quantitative and qualitative data from the trainees along the grant period, combined with feedback from the advisors and OSHA experts reviewing our work, to continuously assess, revise and improve the materials and delivery system.

The grant period was one year for each of the projects. The training sessions using the traditional format took place in venues such as the trade organizations' or contractors' training centers, or other venues provided by the contractors (e.g. warehouse facilities). A typical training session took three hours and followed the flow diagram presented in Fig. 1. The steps in a given session include trainee sign-up; pre-test; PowerPoint presentation (with questions, answers and discussions); post-test (s); and opinion survey. It should be noted that although typically, there is one pre-test at the beginning of the session after sign-up, there may be multiple post-tests given after completing some part of the module. The tests are graded on-site, and the correct answers are shared with the audience, with additional discussions as appropriate to augment learning. A certificate is provided to the trainees to indicate their participation in or completion of the particular training. These certificates are mailed to the trainees.

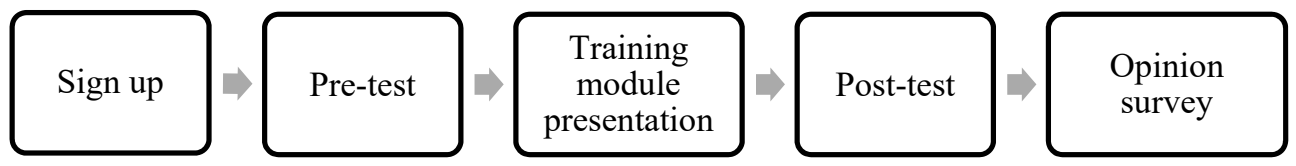

Figure 1: Typical training flow chart.

The online format follows the same logic; however, it is self-paced and no opportunities for any interaction or discussion online are currently available. The portal is accessed by a universal resource locator (URL) link, or by scanning a Quick Response (QR) code (see Fig. 2 for a sample), which is suitable for handheld devices such as cell phones and tablets. This format of delivery has the distinct advantage of flexibility in that it provides on-demand training that can be taken anytime and anywhere at the trainees' convenience. The portal is designed to capture essentially the same type of research data, and has the capability to post the grades earned in the pre-test and post-test(s), while also displaying the correct answers to each question after the test is finalized. A certificate can be downloaded from the computer, laptop, tablet or smart phone upon completion of the training session. There is no time limit. 


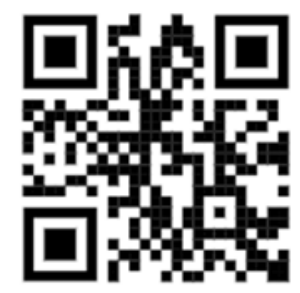

Figure 2: Sample QR code.

Table 1: Training module outlines.

\begin{tabular}{|c|c|}
\hline Silica module & Excavation module \\
\hline 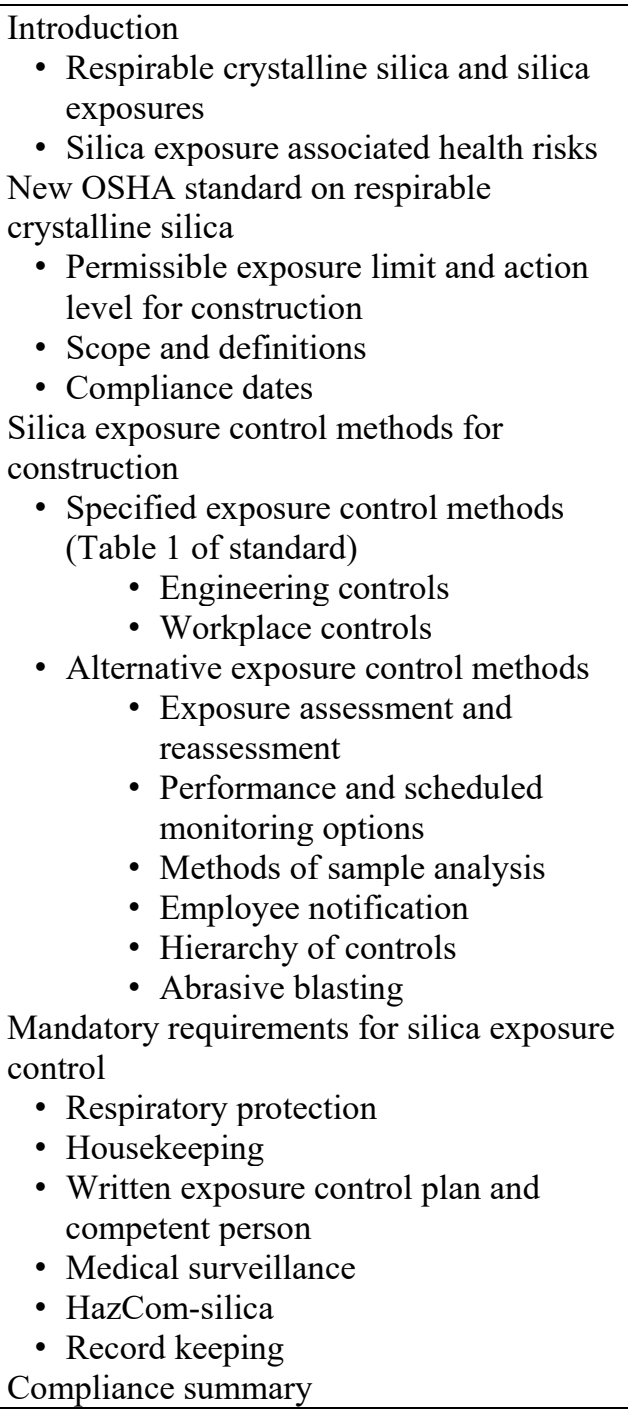 & 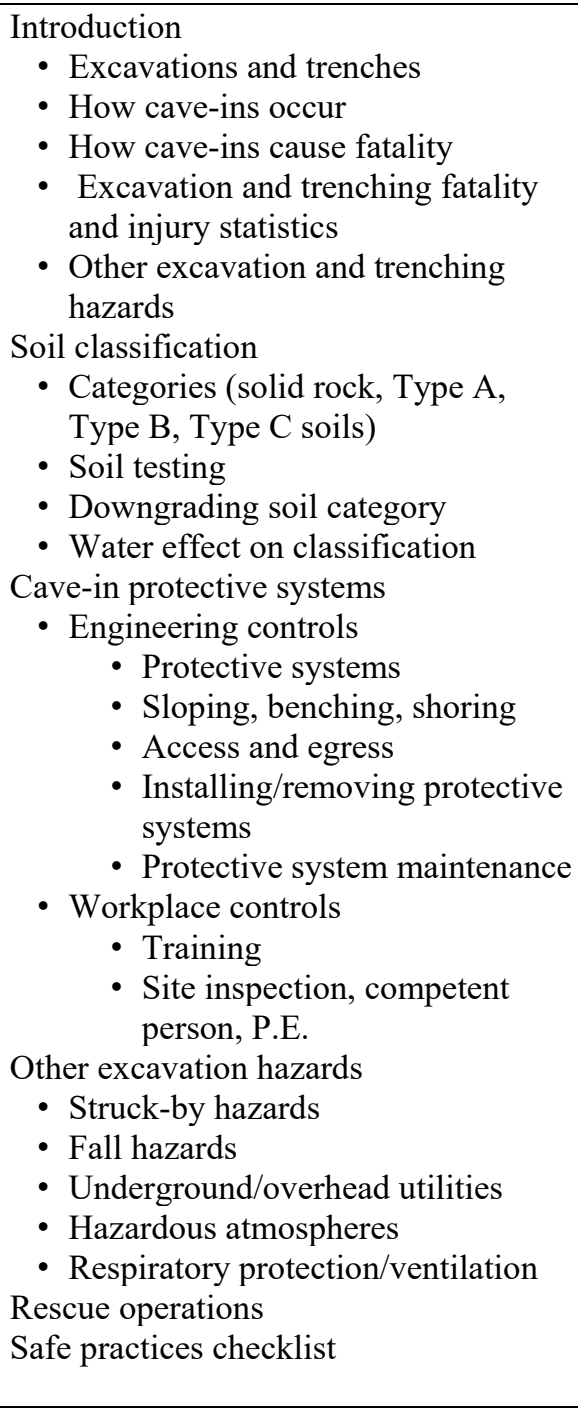 \\
\hline
\end{tabular}




\section{TRAINING EFFECTIVENESS EVALUATION METHODOLOGY}

Evaluation of learning/training effectiveness is essential for gauging the success of a training program. Limited information is available in the literature on this topic. The relevant papers include: Kazan and Usmen [2], Impact Measurement Centre [3], McCann [4], Tamkin et al. [5] and Wang and Wilcox [6]. As discussed by Tamkin et al. [5], Donald Kirkpatrick offers a model for training effectiveness evaluation, which refers to four levels of assessment: Level 1 assessment is the reaction of the trainee to the perceived usefulness of the training received. Level 2 is the learning increment evaluated by comparison of the scores of a pre-test given prior to the PowerPoint instructional module and the post-test(s) covering all or a part of training lecture(s) presented. Level 3 assesses the retention of knowledge and skill gained in initial training as determined by evaluating the trainees' safety behavior after a certain period has elapsed following the initial training. Level 4 is the actual result/impact (in terms of site/company safety improvements) over a period of time using a set of leading and lagging indicators of safety as assessment metrics. In our grant work, we used only Level 1 (derived from the survey) and Level 2 (based on pre-test and post-test scores).

For level 1, the following questions (presented as statements) were included in the opinion survey using a 5-point Likert Scale (1 - strongly disagree, 2 - disagree, 3 - neutral, 4 - agree, 5 - strongly agree):

- SQ1. This safety training improved my knowledge. (PKI - Perceived knowledge improvement)

- SQ2. Overall, the safety training materials presented were easy to understand.

- SQ3. The topics covered was relevant to me.

- SQ4. This training experience will be useful in my work.

For Level 2, the metric for knowledge gain/improvement as a result of training was formulated as

$$
\mathrm{KIR}=\frac{\mathrm{POT}}{\mathrm{PRT}}
$$

where KIR is the knowledge improvement ratio; POT is the post-test result, and PRT is the pre-test result.

The KIR value as originally conceived by Kaya [7] is helpful not only in evaluating the amount of incremental knowledge gain, but also in identifying further training or retraining needed by program participants. KIR greater than 1 illustrates knowledge improvement; KIR less than one implies knowledge regression; KIR of one means no change in knowledge level.

\section{TRAINING EFFECTIVENESS DATA ANALYSIS}

The collected data was statistically analysed using the Statistical Package for the Social Sciences (SPSS) software. The results are presented in the following paragraphs.

\subsection{Trainee demographics}

The silica training program which reached out to 721 personnel, it was found that $48.5 \%$ of the trainees had high school education/GED; and $31.5 \%$ had some college; only $2.5 \%$ lacked a high school diploma. Operating engineers constituted $50 \%$ of the program participants, followed by masons $(11 \%)$, laborers $(10 \%)$, and bricklayers $(9.5 \%)$. Majority of the trainees $(52 \%)$ had more than 20 years of experience, and a small percentage (7.4\%) had less than 10 years of experience. A total of $72 \%$ of the trainees reported that they had prior safety training. 
A total of 405 personnel were trained in the excavation training program, however, data was available for only 176 responses related to education level. Based on this sample, $49 \%$ of the trainees reported to have high school education/GED; $31 \%$ had some college; and bachelor and associate degree holders were $4 \%$ each. The rest of the questions received responses from all 405 participants. Referring to this data, operating engineers populated $39 \%$ of the program; $19 \%$ was construction laborers, and 17\% were pipelayers. Majority of the trainees $(55 \%)$ had 1 to 5 years of experience; $18 \%$ had between 6 and 15 years; while about $19 \%$ had more than 20 years of experience. About $58 \%$ of the trainees had prior safety training.

\subsection{Knowledge improvement}

The results of knowledge improvement analyses for silica and excavation training programs are summarized in Table 2. It was determined that satisfactory performance for any trainee would be achieving a score of 72 (18 correct answers on the pre-test or post-test out of 25 questions, expressed as a percentage). The data can be analysed under four different scenarios as delineated in the table. The separation of the data into four groups is necessitated by the fact that KIR is a ratio while the satisfactory test score is 72 . This means that for very high or very low KIR values there may be extreme situations making the interpretation of results unrealistic.

Table 2: Training knowledge improvement data.

\begin{tabular}{|c|c|c|c|c|}
\hline \multirow[b]{2}{*}{ Scenarios } & \multirow{2}{*}{$\begin{array}{l}\text { Knowledge } \\
\text { Improvement } \\
\text { Ratio (KIR) }\end{array}$} & \multicolumn{3}{|c|}{ Number of trainees } \\
\hline & & $\begin{array}{c}\text { Silica- } \\
\text { Traditional }\end{array}$ & $\begin{array}{c}\text { Excavation - } \\
\text { Traditional } \\
\end{array}$ & $\begin{array}{c}\text { Excavation - } \\
\text { Online }\end{array}$ \\
\hline \multirow{3}{*}{$\begin{array}{l}\text { 1) Pre-test greater than } \\
\text { or equal to } 72 \text { and } \\
\text { Post-test greater than } \\
\text { or equal to } 72\end{array}$} & $<1$ & 21 & 2 & 1 \\
\hline & $=1$ & 38 & 6 & 7 \\
\hline & $>1$ & 188 & 92 & 89 \\
\hline $\begin{array}{l}\text { 2) Pre-test greater than } \\
\text { or equal to } 72 \text { and } \\
\text { Post-test less than } 72\end{array}$ & $<1$ & 8 & 0 & 2 \\
\hline $\begin{array}{l}\text { 3) Pre-test less than } 72 \\
\text { and Post-test greater } \\
\text { than or equal to } 72\end{array}$ & $>1$ & 363 & 68 & 117 \\
\hline \multirow{3}{*}{$\begin{array}{l}\text { 4) Pre-test less than } 72 \\
\text { and Post-test less than } \\
72\end{array}$} & $<<1$ & 8 & 0 & 4 \\
\hline & $=1$ & 19 & 1 & 1 \\
\hline & $>1$ & 76 & 7 & 8 \\
\hline & Total & 721 & 176 & 229 \\
\hline
\end{tabular}

Referring to Table 2 for data pertaining to silica, Scenario 1 depicts the cases where the trainees scored 72 or higher in both the pre-test and the post-test, which represents a total of 247 cases out of 721 , or $34 \%$ of the total population. Interestingly, there were 38 cases with no knowledge improvement $(\mathrm{KIR}=1)$ and 21 cases with knowledge decline $(\mathrm{KIR}<1)$, although the trainees in the latter case still successfully completed the entire training program. There was a very small number of trainees (8) in Scenario 2, representing the people who regressed from a satisfactory to an unsatisfactory score. In this case, the trainee would be considered unsuccessful based on the post-test score, even though $\mathrm{s} / \mathrm{he}$ could have been 
deemed successful just based on the pre-test. Scenario 3 is the most impactful case, with KIR greater than 1, where the trainees increased their knowledge from an unsatisfactory (post-test score below 72) to a satisfactory level (above 72). The number of people in this category was 363 , corresponding to 50 percent of the total population who received silica training. Finally, in Scenario 4 the trainees failed both the pre-test and the post-test; a positive outcome in this case was that 76 trainees $(11 \%)$ improved their knowledge, however this occurred without achieving a satisfactory score.

The same four scenarios also appear in Table 2 for excavation training, which was carried out with lecture-based traditional format and using the online delivery, thus allowing for comparisons. It appears from the data shown in the table that people who received traditional training did better than those who completed online training in Scenario 1. That is, 92 trainees out of 176 total $(55 \%)$ demonstrated knowledge improvement when both the pre-test and post-test scores were above 72 , in comparison to 89 out of 229 people (39\%) showing knowledge improvement when trained online. The numbers in Scenarios 2 and 4 are too small to make any reasonable interpretations. The impactful Scenario 3 for excavation, where 185 out of $405(46 \%)$ trainees experienced knowledge improvement, scoring higher than 72 in pre-test as well as the post-test, offers another interesting observation. While 68 out of 176 trainees $(39 \%)$ exhibited knowledge gain with the traditional training experience, a higher percentage, 55\% (117 out of 229) achieved similar success when training online, suggesting that online training can be more effective than the traditional one, when the trainees start at a lower than satisfactory knowledge level.

\subsection{Perceived knowledge improvement and satisfaction with training}

Trainee responses to the four key questions on the opinion survey are displayed in Table 3. Note that the data shown pertains to the responses comprising Scenario 3, where the KIR's are greater than one while the pre-test scores are less than 72. Only the responses for strongly agree or agree (sum of the two) were included in the analysis. Percentage numbers, calculated as the averages of all responses in Scenario 3, encompass traditional silica training, traditional excavation training and online excavation training. It is clear from these numbers that, with one exception of $62 \%$ for online excavation training, more than two-thirds of the trainees agreed or strongly agreed with all of the four statements given in the survey questions, indicating rather strong satisfaction with their learning, as well as training experience.

Table 3: Percentages of responses to key survey questions for Scenario 3.

\begin{tabular}{|c|c|c|c|}
\hline \multirow{2}{*}{$\begin{array}{c}\text { Survey } \\
\text { questions }\end{array}$} & \multicolumn{3}{|c|}{ Agree and strongly agree responses to survey questions } \\
\cline { 2 - 4 } & $\begin{array}{c}\text { Traditional } \\
\text { silica training }\end{array}$ & $\begin{array}{c}\text { Traditional } \\
\text { excavation training }\end{array}$ & $\begin{array}{c}\text { Online excavation } \\
\text { training }\end{array}$ \\
\hline SQ1 & 85 & 91 & 74 \\
\hline SQ2 & 72 & 90 & 76 \\
\hline SQ3 & 77 & 79 & 62 \\
\hline SQ4 & 79 & 88 & 69 \\
\hline
\end{tabular}

SQ1 was aimed at measuring knowledge improvement as perceived by the trainees after completing the training. The percentages presented in the table show that traditional excavation training achieved the strongest favorable response (91\%), followed by traditional silica training and online excavation training. SQ2 was about the ease of understanding of 
the training materials by the trainees. Again, traditional excavation training topped the responses at $90 \%$; however, for this question online excavation training drew better responses than traditional silica training. SQ3 addressed the relevance of the topic to the trainees. While the traditional format was quite well received by the trainees for silica and excavation, the online excavation training experience produced mixed results for this question. Finally, SQ4 explored the trainees' perception on how much they thought the training received would be useful in their work. Once more, the responses from the online excavation training group were relatively weaker than the other two.

Overall, it is fair to state that both training programs were very well received by the trainees, and in the case of traditional excavation training, the responses were overwhelmingly positive. Online training, with one exception, produced the weakest responses overall; it is believed that this may be due to the open/unsupervised participation by the trainees whose backgrounds and motivations might vary. This aspect needs further investigation. Comparing silica with excavation, it seems that the latter got higher (better) percentages for all four survey questions. This is more likely because the OSHA standard on excavation and trenching safety has been in effect for several decades, whereas the OSHA silica standard is brand new. Mostly, all personnel receiving the silica training were being exposed to the contents as a first time experience.

\subsection{KIR vs. PKI relationship}

An attempt was made, as a limited side study, to analyse and determine if there was a possible correlation between KIR and PKI. Cross tabulation analysis was performed with the data (100 trainees) drawn from Scenario 1. It was not possible to do cross-tabulation analysis for Scenarios 2 and 3 because of the fact that KIR is a constant in these cases; it was also unfeasible to perform crosstab analysis on Scenario 4 because of the very small amount of data available. Results for Scenario 1 are given in Table 4. The Chi-square and $p$ (significance) values included in the table were computed by SPSS. Based on these results, it was not possible to obtain a statistically significant correlation between the two variables, meaning that PKI and KIR are independent from each other and should be interpreted individually. This observation indicates that even though trainees may perceive that they increased their knowledge, they may not show this improvement in their post-test scores; vice versa is also true. There have been studies investigating the factors affecting the existence of correlations between Level 1 and Level 2 learning effectiveness [8], [9]. It has

Table 4: Crosstab analysis of KIR vs. PKI for Scenario 1.

\begin{tabular}{|l|c|c|c|c|c|c|c|c|c|}
\hline \multirow{2}{*}{$\begin{array}{l}\text { Perceived } \\
\text { Knowledge } \\
\text { Improvement (PKI) }\end{array}$} & \multicolumn{7}{|c|}{ Knowledge Improvement Ratio (KIR) } \\
\cline { 2 - 11 } & \multicolumn{2}{|c|}{$\begin{array}{c}\text { Traditional silica } \\
\text { training }\end{array}$} & \multicolumn{3}{c|}{$\begin{array}{c}\text { Traditional } \\
\text { excavation training }\end{array}$} & \multicolumn{3}{|c|}{$\begin{array}{c}\text { Online excavation } \\
\text { training }\end{array}$} \\
\cline { 2 - 11 } & $<1$ & $=1$ & $>1$ & $<1$ & $=1$ & $>1$ & $<1$ & $=1$ & $>1$ \\
\hline Strongly disagree & 0 & 1 & 5 & 0 & 0 & 0 & 0 & 0 & 4 \\
\hline Disagree & 1 & 1 & 4 & 0 & 1 & 3 & 0 & 0 & 0 \\
\hline Neutral & 1 & 3 & 25 & 0 & 2 & 8 & 0 & 0 & 17 \\
\hline Agree & 9 & 14 & 42 & 1 & 1 & 38 & 1 & 3 & 49 \\
\hline Strongly agree & 10 & 19 & 112 & 1 & 2 & 43 & 0 & 4 & 19 \\
\hline Total & 21 & 38 & 188 & 2 & 6 & 92 & 1 & 7 & 89 \\
\hline$\chi^{2}$ and p-value & $\chi^{2}=7.11, p=0.525$ & $\chi^{2}=7.36, p=0.288$ & $\chi^{2}=6.19, p=0.402$ \\
\hline
\end{tabular}


been found that correlations may or may not be strong depending on various factors most of which are trainee-related, e.g. culture, gender, education level. Such an effort was outside the scope of the work reported in this paper.

\section{CONCLUSIONS}

It can be concluded that knowledge improvements on safety and health standards and their implementation can be realized by training construction trades and other personnel by the traditional and online delivery systems. Knowledge improvement can be quantified by the Knowledge Improvement Ratio (KIR) metric, which is calculated by dividing the post-test score by the pre-test score of a trainee participating in a training session. Another way to get an indication of knowledge improvement is to have the trainees express their perceptions of whether or not their knowledge has improved as a result of completing a training program (PKI), which is usually determined from an opinion survey given at the end of a training session. Online training can follow the same steps as the traditional and has the distinct advantage of reaching out to individuals in remote locations at their convenience in terms of time and place, while generally producing cost savings. On the other hand, traditional training is likely to achieve better knowledge improvement because of the ability of the trainees to interact with the trainers in the course of training and receive answers to their questions with explanations. It is possible, however, to build interactive features into online training, and this is highly recommended. Based on a limited study using Scenario 1 data, it was found that there was no statistically significant correlation between KIR and PKI. We recommend that further study be performed on this relationship, and additionally, the Kirkpatrick learning assessment model be extended into level 3 and level for 4 evaluations to further analyse training effectiveness.

\section{ACKNOWLEDGEMENTS}

The funding provided by the US Department of Labor, through OSHA's Susan Harwood Training Program for grants SH-29666-SH6 (silica) and SH-31218-SH7 (excavation) to make this study possible is gratefully acknowledged. The findings of this study reflect the views of the authors, and not those of the sponsor, The US Department of Labor, OSHA.

\section{REFERENCES}

[1] National Occupational Research Agenda For Construction, www.cdc.gov/nora/ councils/const/pdfs/National_Occupational_Research_Agenda_for_Construction_June 2018_508.pdf. Accessed on: 3 May 2019.

[2] Kazan, E. \& Usmen, M.A., Worker safety and injury severity analysis of earthmoving equipment accidents. Journal of Safety Research, 65, pp. 73-81, 2018.

[3] Impact Measurement Centre, Measuring the impact of training and development in the workplace. www.researchgate.net/profile/Anantjyoti_Badgaiyan/post/What_is_ a good_questionnaire_on_Impact_of_training_on_employee_performance/attachment $/ 5$ 9d6213a79197b807797fa11/AS\%3A295353002807325\%401447429052227/downloa d/Measuring_the_Impact__Final_Report.pdf. Accessed on: 23 Apr. 2019.

[4] McCann, M., Heavy equipment and truck-related deaths on excavation work sites. Journal of Safety Research, 37(5), pp. 511-517, 2006.

[5] Tamkin, P., Yarnall, J. \& Kerrin, M., Kirkpatrick and beyond: A review of models of training evaluation. Institute for Employment Studies: Brighton, UK. www.employment-studies.co.uk/system/files/resources/files/392.pdf. Accessed on: 23 Apr. 2019. 
[6] Wang, G.G. \& Wilcox, D., Training evaluation: Knowing more than is practiced. Advances in Developing Human Resources, 8(4), pp. 528-539, 2006.

[7] Kaya, S., Effect of construction worker demographics on e-learning with hazard communication standard. Thesis, Wayne State University. https://digitalcommons.wayne.edu/oa theses/381. Accessed on: 16 May 2019.

[8] Ziegler, B. \& Montplaisir, L., Student perceived and determined knowledge of biology concepts in an upper-level biology course. CBE_Life Sciences Education, 13(2), pp. 322-330, 2014.

[9] Grant, D.M., Malloy, A.D. \& Murphy, M.C., A comparison of student perceptions of their computer skills to their actual abilities. Journal of Information Technology Education, 8, pp. 141-160, 2009. 